"Synthesis and properties of oligonucleotides carrying isoquinoline imidazo[1,2-a]azine fluorescente units" Pérez-Rentero, S., Kielland, N., Terrazas, M., Lavilla, R., Eritja, R. Bioconjugate Chem., 21(9), 1622-1628 (2010).PMID: 20687535, doi: 10.1021/bc1000966

\title{
Synthesis and properties of oligonucleotides carrying isoquinoline imidazo[1,2-a]azine fluorescent units.
}

Sónia Pérez-Rentero ${ }^{\ddagger}$, Nicola Kielland ${ }^{\S}$, Montserrat Terrazas ${ }^{\ddagger}$, Rodolfo Lavilla $^{*},{ }^{, \dagger}$, and Ramon Eritja $^{*}, \ddagger$

${ }^{\ddagger}$ Institute for Research in Biomedicine, IQAC-CSIC, CIBER-BBN Networking Centre on Bioenginnering, Biomaterials and Nanomedicine. Baldiri Reixac 10, 08028 Barcelona, Spain.

${ }^{\S}$ Institute for Research in Biomedicine. Laboratory of Organic Chemistry, Faculty of Pharmacy. University of Barcelona. Baldiri Reixac 10-12, 08028 Barcelona, Spain.

${ }^{\dagger}$ Laboratory of Organic Chemistry, Faculty of Pharmacy. University of Barcelona. Avda Joan XXIII s/n, 08028 Barcelona, Spain.

TITLE RUNNING HEAD. Fluorescent labeling of oligonucleotides

*To whom correspondence should be addressed: phone 34-934039942 (email) recgma@cid.csic.es; rlavilla@pcb.ub.es 
Abstract. Oligonucleotides carrying novel fluorescent compounds with a dipolar isoquinoline imidazo[1,2-a]azine core were prepared. Analysis of the melting curves demonstrates that DNA duplexes carrying these fluorescent labels at their ends have a slight increase on DNA duplex stability. The UV absorption and fluorescent properties of the oligonucleotide conjugates were analyzed. The fluorescent label is sensitive to duplex formation as cooperative melting curves are also observed at $366 \mathrm{~nm}$ and fluorescence has a large increase upon denaturation. Cell-uptake studies allow observation of these fluorescently-labeled oligonucleotides internalized into HeLa cells.

KEYWORDS. Oligonucleotides, fluorescence, multicomponent reactions.

\section{Introduction}

There is a considerable interest in the development of new dyes and the introduction of these into biomolecules such as peptides, proteins and nucleic acids (1). Furthermore, the development of new methodologies for the selective and straightforward modification of biomolecules is having an increasing impact on biopharmaceuticals. When fluorescent molecules are attached to biomolecules that are not fluorescent, the resulting new entity acquires the fluorescent properties. Thus, fluorescent labels allow sensitive and selective detection of a specific component of complex biomolecular assemblies. Fluorescence-labeled oligonucleotides have large number of applications in several fields, such as biotechnology (2), cell biology (3), molecular biology (4), and biophysics (5). Therefore, the development of new fluorescent labels for oligonucleotides is of particular relevance $(6,7)$.

Recently, we described the synthesis of a new class of fluorescent mesoionic acid fluorides using a multicomponent strategy. The reaction involves the participation of an azine, an isocyanide and a fluorinated anhydride and yields dipolar derivatives with an isoquinoline imidazo[1,2-a]azine core (see scheme 1) (8). These compounds are fluorescent, and when trifluoroacetic anhydride is used, they contain a reactive acid fluoride group that can be used to introduce the fluorescent label, by means of amide formation, into biomolecules that carry amino groups. The modular character of this 
multicomponent reaction (MCR) (9) allows the convergent synthesis of a large variety of structural analogs in a single step. Thus both the fluorescent and biological properties of the dye can be optimized for specific applications. In this respect, the present study determines the features of the conjugation of these stable dipolar acyl fluorides with oligonucleotides, a fruitful strategy often used in peptide synthesis (10), which to our knowledge is unprecedented in the oligonucleotide field.

Here we report the conjugation of mesoionic acid fluorides $\mathbf{1 a}$ and $\mathbf{1 b}$ with oligonucleotides carrying alkyl amino groups (scheme 2) and demonstrate that fluorescence-labeled oligonucleotides can be prepared in good yields directly from the reaction of amino-oligonucleotides and mesoionic acid fluorides in aqueous media. Dipoles 1a and $\mathbf{1 b}$, bearing respectively cyclohexyl and benzyl group as substituents at the imidazole nitrogen, were selected from a set of described analogues for the following reasons. First, they can be synthesized in multigram scale with a simple methodology and are well characterized (X-Ray, NMR and spectroscopy); also their substituents at the imidazole nitrogen (cyclohexyl and benzyl) featuring relevant differences in terms of shape, volume, polarity and conformational behavior, may confer to the corresponding bioconjugates distinct properties. Furthermore both residues are chemically stable, unlikely to suffer degradation in physiological media and, from an exploratory point of view, easy to replace by a wide number of analogues.

Our results indicate that the novel fluorescent oligonucleotides show potentially interesting properties for denaturation monitoring procedures as well as for cellular uptake studies.

\section{Experimental Procedures}

The phosphoramidites and ancillary reagents used during oligonucleotide synthesis were from Applied Biosystems (PE Biosystems Hispania S.A., Spain) and Link Technologies Ltd. (Scotland). The rest of the chemicals were purchased from Aldrich, Sigma or Fluka (Sigma-Aldrich Química S.A., Spain). 1Cyclohexyl-3-(fluorocarbonyl)-2-oxo-2,3-dihydro-1H-imidazo[2,1-a]isoquinolin-4-ium-3-ide (1a), 1benzyl-3-(fluorocarbonyl)-2-oxo-2,3-dihydro-1H-imidazo[2,1-a]isoquinolin-4-ium-3-ide

(1b) $1-$ cyclohexyl-3-(4-methoxybenzylcarbamoyl)-2-oxo-2,3-dihydro-1H-imidazo[2,1-a]isoquinolin-4-ium-3- 
ide (1c) and 1-cyclohexyl-3-(methoxycarbonyl)-2-oxo-2,3-dihydro-1H-imidazo[2,1-a]isoquinolin-4ium-3-ide (1d) were prepared following literature procedures (8) (scheme 1).

Synthesis of oligonucleotides. Oligonucleotide sequences A: 5'-CCAATTGG-3', and B: 5'TTCCGGAA-3' and C: 5'-CTCTCGCACCCATCTCTCTCCTTCT-3' were prepared on an automatic Applied Biosystems 3400 DNA synthesizer on 0.2 - or $1-\mu$ mol scale using commercially available chemicals. The sequences were prepared with and without the amino group at the 3 '-end. The synthesis was carried out using the standard phosphite triester methodology and a controlled-pore-glass support carrying the $2-(N-\{[(9 H$-fluoren-9-yl)methoxy $]$ carbonyl $\}$-4-aminobutyl)propane-1,3-diol linker (11) (scheme 2) or in regular low-volume (LV200) polystyrene supports. The benzoyl (Bz) group was used to protect the amino group of $\mathrm{dC}$ and $\mathrm{dA}$, and the isobutyryl (ibu) group to protect $\mathrm{dG}$. Coupling yields were $>95 \%$. The last DMT group was removed at the end of the synthesis. The oligonucleotide was deprotected and cleaved from the support by treatment with aqueous concentrated ammonia for $12 \mathrm{~h}$ at $55^{\circ} \mathrm{C}$. Under these conditions, all protecting groups, including Fmoc were removed to yield unprotected 3'-amino-oligonucleotide. The mixture was filtered and the ammonia solution was concentrated to dryness. The residue was passed through a Dowex $50 \times 4\left(\mathrm{Na}^{+}\right.$form) column to exchange ammonium ions for $\mathrm{Na}^{+}$ions. The solution was analyzed by HPLC and used directly in the dye conjugation. Analytical HPLC solutions: Solvent A: 5\% acetonitrile (MeCN) in $100 \mathrm{mM}$ triethylammonium acetate $(\mathrm{pH}=7)$ and solvent $\mathrm{B}: 70 \% \mathrm{MeCN}$ in $100 \mathrm{mM}$ triethylammonium acetate $(\mathrm{pH}=7)$. Column: X-Bridge ${ }^{\mathrm{TM}} \mathrm{OST} \mathrm{C} 18(2.5 \mu \mathrm{m} 4,6 \times 50 \mathrm{~mm})$. Flow rate: $1 \mathrm{~mL} / \mathrm{min}$. Conditions for the analysis of octamers: $10 \mathrm{~min}$ linear gradient from $0-30 \% \mathrm{~B}$ at $60^{\circ} \mathrm{C}$; for the analysis of 25 mer: 4 min linear gradient from $0-12 \% \mathrm{~B}$, then 6 min linear gradient from $12-50 \% \mathrm{~B}$ at $60^{\circ} \mathrm{C}$ ). The desired oligonucleotides eluted at 2.5-3.5 min. Alternatively, oligonucleotides were purified by HPLC (see below).

Octamer sequence A (200 nmol scale): $33 \%$ yield $\left(5 \mathrm{OD}_{260}\right) \mathrm{t}_{\mathrm{R}}=2.6$ min. Octamer sequence A 3'- $\mathrm{NH}_{2}(1$ $\mu \mathrm{mol}$ scale): $47 \%$ yield $\left(36 \mathrm{OD}_{260}\right.$ ), $\mathrm{t}_{\mathrm{R}}=2.6 \mathrm{~min}$. MALDI-TOF MS $\mathrm{m} / \mathrm{z}$ (negative mode, THAP-CA, [M- 
$\mathrm{H}^{-}$) expected for $\mathrm{C}_{85} \mathrm{H}_{106} \mathrm{~N}_{31} \mathrm{O}_{50} \mathrm{P}_{8} 2617.8$, found 2618.7). Octamer sequence B (200 nmol scale): $39 \%$ yield $\left(6 \mathrm{OD}_{260}\right) \mathrm{t}_{\mathrm{R}}=3.2 \mathrm{~min}$. Octamer Sequence B 3'- $\mathrm{NH}_{2}\left(1 \mu \mathrm{mol}\right.$ scale): $54 \%$ yield $\left(42 \mathrm{OD}_{260}\right), \mathrm{t}_{\mathrm{R}}=3.2$ min. MALDI-TOF MS m/z (negative mode, THAP-CA, [M-H] ${ }^{-}$) calculated for $\mathrm{C}_{85} \mathrm{H}_{106} \mathrm{~N}_{31} \mathrm{O}_{50} \mathrm{P}_{8} 2617.8$, found 2617.9). 25 mer sequence $\mathrm{C} 3$ ' $-\mathrm{NH}_{2}\left(1 \mu \mathrm{mol}\right.$ scale): $58 \%$ yield $\left.118 \mathrm{OD}_{260}\right), \mathrm{t}_{\mathrm{R}}=4.0 \mathrm{~min}$. MALDITOF MS m/z (negative mode, THAP-CA, [M-H] $]^{-}$) expected for $\mathrm{C}_{244} \mathrm{H}_{301} \mathrm{~N}_{73} \mathrm{O}_{159} \mathrm{P}_{25} 7600$, found 7603.6).

General protocol for conjugation. The amino-oligonucleotides were reacted with 1-cyclohexyl-3(fluorocarbonyl)-2-oxo-2,3-dihydro-1H-imidazo[2,1-a]isoquinolin-4-ium-3-ide (1a) or 1-benzyl-3(fluorocarbonyl)-2-oxo-2,3-dihydro-1H-imidazo[2,1-a]isoquinolin-4-ium-3-ide (1b) or with fluorescein isothiocyanate (FITC) (Isomer I, Sigma) as follows. Oligonucleotides (7 O.D.) were dissolved with 250 $\mu \mathrm{L}$ of an aqueous solution of $\mathrm{NaHCO}_{3} 0.2 \mathrm{M}(\mathrm{pH}=9)$. Then, 10 equiv of a solution of compound 1a or 1b or FITC in $0.25 \mathrm{ml}$ of $N, N$-dimethylformamide (DMF) were added and the mixture was left to react for $8 \mathrm{~h}$ at room temperature. Then $100 \mu \mathrm{L}$ of an aqueous solution of $\mathrm{NaHCO}_{3} 0.2 \mathrm{M}(\mathrm{pH}=9)$ and an additional 10 equiv of compound 1a or $\mathbf{1 b}$ in $100 \mu \mathrm{L}$ of DMF were added and the mixture was left overnight at room temperature. The mixtures were concentrated to dryness, and the residues were dissolved in $1 \mathrm{ml}$ of $\mathrm{H}_{2} \mathrm{O}$. The solutions were purified by Sephadex G-25 (NAP-10 columns). The fractions containing oligonucleotides were analyzed by HPLC as described above (Figure 1). Octamer 5 and 25 mer 6 were used in the next step without further purification. Octamers 2-4 were purified by HPLC on a Nucleosil 120C18 $(10 \mu \mathrm{m}, 200 \times 10 \mathrm{~mm})$ column. Flow rate: $3 \mathrm{~mL} / \mathrm{min}$. Conditions: $10 \mathrm{~min}$ linear gradient from $0-30 \% \mathrm{~B}$, then a 10 min linear gradient from $30-100 \% \mathrm{~B}$. The resulting products were desalted with Sephadex G-25 (NAP-5 Column). The coupling efficiency was determined by HPLC analyses (Octamer 2 91\%, Octamer 3 91\%, Octamer 4 94\%, 25mer 6 85\%, Octamer 5 (FITC) 94\%). HPLC solutions as described above. Column: X-Bridge ${ }^{\mathrm{TM}}$ OST C18 (2.5 $\left.\mu \mathrm{m} 4,6 \mathrm{x} 50 \mathrm{~mm}\right)$. Flow rate: 1 $\mathrm{mL} / \mathrm{min}$. Conditions: 4 min linear gradient from $0-12 \% \mathrm{~B}$, then a 1 min linear gradient from $12-40 \% \mathrm{~B}$, then 5 min linear gradient from $40-45 \% \mathrm{~B}$ at $60^{\circ} \mathrm{C}$. The purified oligomers were analyzed by $\mathrm{MS}$ (MALDI-TOF) and UV-vis (Table 1). 
Octamer 2: $39 \%$ yield $\left(2.7 \mathrm{OD}_{260}\right), \mathrm{t}_{\mathrm{R}}=6.7 \mathrm{~min} ., \quad \lambda=260$ and $347 \mathrm{~nm}$, MALDI-TOF MS $\mathrm{m} / \mathrm{z}$ negative mode, THAP-CA, [M-H] $]^{-}$calculated for $\mathrm{C}_{103} \mathrm{H}_{122} \mathrm{~N}_{33} \mathrm{O}_{52} \mathrm{P}_{8} 2910.1$, found 2911.8.

Octamer 3: $54 \%$ yield $\left(3.8 \mathrm{OD}_{260}\right), \mathrm{t}_{\mathrm{R}}=6.7 \mathrm{~min} ., \quad \lambda=260$ and $346 \mathrm{~nm}$, MALDI-TOF MS $\mathrm{m} / \mathrm{z}$ negative mode, THAP-CA, [M-H] ${ }^{-}$calculated for $\mathrm{C}_{103} \mathrm{H}_{122} \mathrm{~N}_{33} \mathrm{O}_{25} \mathrm{P}_{8} 2910.1$, found 2906.8.

Octamer 4: $26 \%$ yield $\left(1.8 \mathrm{OD}_{260}\right), \mathrm{t}_{\mathrm{R}}=6.4 \mathrm{~min} ., \quad \lambda=260$ and $345 \mathrm{~nm}$, MALDI-TOF MS $\mathrm{m} / \mathrm{z}$ negative mode, THAP-CA, [M-H] calculated for $\mathrm{C}_{104} \mathrm{H}_{118} \mathrm{~N}_{33} \mathrm{O}_{52} \mathrm{P}_{8} 2918.3$, found 2914.9.

Octamer 5: $84 \%$ yield $\left(5.9 \mathrm{OD}_{260}\right), \mathrm{t}_{\mathrm{R}}=5.8 \mathrm{~min} ., \quad \lambda=260$ and $493 \mathrm{~nm}$, MALDI-TOF MS $\mathrm{m} / \mathrm{z}$ negative mode, THAP-CA, [M-H] $]^{-}$calculated for $\mathrm{C}_{106} \mathrm{H}_{128} \mathrm{~N}_{32} \mathrm{O}_{55} \mathrm{P}_{8} \mathrm{~S}$ 3008.9, found 3004.0.

25 mer 6 (from $\left.30 \mathrm{OD}_{260}\right)$ : $71 \%$ yield $\left(21.3 \mathrm{OD}_{260}\right), \mathrm{t}_{\mathrm{R}}=8.3 \mathrm{~min}(4-\mathrm{min}$ linear gradient from $0-12 \% \mathrm{~B}$, then 6-min linear gradient from $12-50 \% \mathrm{~B}$, at $60^{\circ} \mathrm{C}$ ), $\lambda=268$ and $348 \mathrm{~nm}$; MALDI-TOF MS $\mathrm{m} / \mathrm{z}$ negative mode, THAP-CA, [M-H] $]^{-}$expected 7892.3, found 7870.2.

Melting experiments. Melting experiments were performed in duplicate at concentrations ranging from 1.5-14 $\mu \mathrm{M}$ of duplex. Solutions of each oligonucleotide were mixed in a solution containing $1 \mathrm{M}$ $\mathrm{NaCl}$ and $100 \mathrm{mM}$ sodium phosphate buffer $\mathrm{pH}=7$. The DNA concentrations were determined by UVabsorbance measurements $(260 \mathrm{~nm})$ at $80^{\circ} \mathrm{C}$, using the $\varepsilon_{260}$ values calculated by the nearest-neighbor method for the DNA coil state. For octamer 5 the $\varepsilon_{260}$ value was calculated by the nearest-neighbor method as well and adding the contribution of fluorescein (the extinction coefficient of fluorescein (measured as FITC) at $260 \mathrm{~nm}$ is around $13.7 \mathrm{mM}^{-1} \mathrm{~cm}^{-1}$ ). Samples were heated at $90^{\circ} \mathrm{C}$ for $5 \mathrm{~min}$, allowed to cool slowly to room temperature to induce annealing, and then kept overnight in a refrigerator $\left(4^{\circ} \mathrm{C}\right)$.

Melting curves were recorded by heating the samples with a temperature controller from 15 to $80^{\circ} \mathrm{C}$ at a constant rate of $1^{\circ} \mathrm{C} / \mathrm{min}$ and monitoring the absorbance at $260 \mathrm{~nm}$. During the experiment, when the temperature was below $25^{\circ} \mathrm{C}$, argon was flushed to prevent water condensation on cuvettes. Absorption 
spectra and melting experiments (absorbance vs. temperature) were recorded in 1-cm-path-length cells. Melting curves were analyzed by computer-fitting the denaturation data, using Meltwin 3.5 software. Melting temperatures $(\mathrm{Tm})$ decreased with the concentration $c$, as expected for a bimolecular reaction (12). The plot of $1 / \mathrm{Tm} v s$. lnc was linear, giving a slope and a $y$-intercept, from which $\Delta H, \Delta S$ and $\Delta G$ were obtained (Table 2).

\section{Fluorescence analysis.}

Fluorescence spectra were measured in solutions containing $1 \mathrm{M} \mathrm{NaCl}$ and $100 \mathrm{mM}$ sodium phosphate buffer $(\mathrm{pH}=7)$ at a concentration of $2.3 \mu \mathrm{M}$. Excitation was set at $345 \mathrm{~nm}$ for octamers 2-4 and $493 \mathrm{~nm}$ for octamer 5. Fluorescence spectra were measured before $\left(\mathrm{F}_{\mathrm{D}}\right)$ and after $\left(\mathrm{F}_{\mathrm{RC}}\right)$ duplex denaturation to yield relative fluorescence intensity $\left.\left(\mathrm{F}_{\mathrm{RC}} / \mathrm{F}_{\mathrm{D}}\right)\right)$. Results are shown in Figure 2 and Table 4.

\section{Flow cytometry experiments.}

HT-29 cells were incubated for $8 \mathrm{~h}$ with dipole 1c at concentrations of $2 \mu \mathrm{M}, 5 \mu \mathrm{M}, 10 \mu \mathrm{M}, 20 \mu \mathrm{M}$ and $40 \mu \mathrm{M}$ in a low glucose DMEM (Biological Industries) medium in the absence of phenol red. A blank control was also prepared. The supernatant was separated and placed in falcon tubes. The cells were treated with trypsin and placed in the corresponding falcon tubes. Each tube was centrifuged for 4 min at 2000 RPM. The supernatant was removed and PBS $(500 \mu \mathrm{L})$ was added to each tube. The samples were treated with a propidium iodide solution $(5 \mu \mathrm{L}$ of a $1 \mu \mathrm{g} / \mathrm{mL}$ solution $)$ and analyzed with a Cell Lab Quanta SC cytometer (Beckman Coulter).

\section{Confocal microscopy experiments}

HT-29 cells were incubated with dipole 1c and 1d $(20 \mu \mathrm{M})$ for $2 \mathrm{~h}$ in a DMEM medium without phenol red. The living cells were treated with the plasmatic membrane marker WGA (Texas Red-x)-D (excitation at $595 \mathrm{~nm}$, emission $615 \mathrm{~nm}$ ). After $15 \mathrm{~min}$ the cells were analyzed in vivo with a Leica TCS SP2 confocal microscope (excitation at $350 \mathrm{~nm}$, emission between 400 and $500 \mathrm{~nm}$ ). In these 
experiments, a blank control with the cells in the absence of dipole 1c or its conjugate was analyzed. The intensity of the laser was adjusted in order to prevent detection of autofluorescent processes. Products 1c and 1d were detected in the cytoplasmatic region and they formed well defined aggregates (see Supporting Information). Using the same procedure, HeLa cells were incubated with 1c and oligonucleotide $6(20 \mu \mathrm{M})$ for $4 \mathrm{~h}$. While 1c showed the same result as in the previous experiment, no fluorescence was detected using oligonucleotide 6. In the presence of Lipofectamine ${ }^{\mathrm{TM}} 2000$ oligonucleotide 6 penetrated the cytoplasmatic region.

\section{Results and Discussion.}

Synthesis and thermodynamic properties of fluorescence labeled oligonucleotides

Small ligands can be incorporated into synthetic oligonucleotides at specific sites by preparing oligonucleotides carrying aliphatic amino groups and performing a conjugation reaction with the carboxylic derivatives of the ligands $(11,13,14)$. This strategy was used to incorporate the acyl fluorides derivatives 1a and $\mathbf{1 b}$ into oligonucleotides (Scheme 2). Oligonucleotide sequences (Table 1) carrying an amino group at the 3 '-end were assembled using a controlled pore glass support carrying the 2-(N$\{[(9 H$-fluoren-9-yl)methoxy $]$ carbonyl $\}$-4-aminobutyl)propane-1,3-diol linker (11) and following standard protocols. The resulting oligonucleotides were used in the reaction with acyl fluorides (Scheme $1)$.

Amino-oligonucleotides were reacted with an excess of acyl fluorides $\mathbf{1 a}$ and $\mathbf{1 b}$ in aqueous dimethylformamide (DMF) mixtures at $\mathrm{pH} 9$ and room temperature. In these mild conditions the desired fluorescent oligonucleotides 2-4, 6 were produced in good yields as shown by the presence of new products with higher retention time, which were characterized by mass spectrometry and UV spectra (Figure 1 and Table 1). In addition we have prepared the fluoresceine-labelled octamer 5 by reaction of the appropriate amino-octamer with fluoresceine isothiocyanate (FITC). 
The hybridization properties of the oligonucleotides carrying the isoquinoline imidazo[1,2-a]azine group were measured spectrophotometrically on the self-complementary octamer duplexes 2-4. Unmodified octamers were included for comparison purposes (Table 2). The duplex formed by sequence A which carried two molecules of compound 1a (octamer 2), melted at $41.1{ }^{\circ} \mathrm{C}(\Delta \mathrm{G} 20.6 \mathrm{kcal} /$ mol), while the unmodified duplex melted at $33.3{ }^{\circ} \mathrm{C}(\Delta \mathrm{G} 18.0 \mathrm{kcal} / \mathrm{mol})$. This observation implies an increase in duplex stability of $3.8^{\circ} \mathrm{C}(\Delta \Delta \mathrm{G} 1.3 \mathrm{kcal} / \mathrm{mol})$ per fluorescent molecule. In contrast, the duplex formed by sequence A, carrying two molecules of compound $\mathbf{1 b}$ (octamer $\mathbf{4}$ ), melted at $34{ }^{\circ} \mathrm{C}$ ( $\Delta \mathrm{G} 17.7 \mathrm{kcal} / \mathrm{mol})$, thereby indicating a small destabilization of the duplex. This effect should reflect the previously mentioned differences between the substituents on the imidazole nitrogen of the dipoles, presumably arising from the distinct interactions at the conformational level of the cyclohexyl and benzyl groups with the oligonucleotide backbone. The stabilizing properties of compound 1a were slightly increased in octamer $3(\Delta \Delta \mathrm{G} 2.0 \mathrm{kcal} / \mathrm{mol})$, thereby indicating that the stabilizing properties of this compound are not dependent on the DNA sequence at the end as octamer 3 has A.T base pairs while octamer 2 has G.C base pairs.

Preliminary conformational studies of the linkers containing cyclohexyl or benzyl substituents by means of computer-based molecular modeling (Spartan'04 and Hyperchem'08; molecular mechanics conformational search and geometry optimization) suggest that in the lower energy conformations, the isoquinoline imidazo[1,2-a]azine core containing a cyclohexyl substituent stacks over the terminal guanine nucleobase, at a distance of approximately 3 to $4 \AA$, whereas the isoquinoline imidazo[1,2a]azine core containing a benzyl substituent does not interact significantly with the terminal guanine (see Supplementary Figure S1). These studies were carried out by keeping frozen the duplex of DNA and by allowing the linker to move freely during the calculations. In order to explore the rotational freedom of the cyclohexyl or benzyl-fluorescent isoquinoline imidazo[1,2-a]azine in more detail and to determine the dynamic behavior of the conjugates, Molecular Dynamics simulations and NMR studies 
on these modified duplexes would be necessary. A comprehensive study is currently under way in our laboratory.

UV spectra of the modified oligonucleotides $2-4$ at $20^{\circ} \mathrm{C}$ (duplex) and $70^{\circ} \mathrm{C}$ obtained in a solution containing $1 \mathrm{M} \mathrm{NaCl}$ and $100 \mathrm{mM}$ sodium phosphate buffer of $\mathrm{pH}=7$ at a concentration of $6.8 \mu \mathrm{M}$ are shown in Figure 2a. The maximum caused by the isoquinoline derivative shows a slight shift depending on the temperature. The hyperchromism in the absorption spectra at $70^{\circ} \mathrm{C}$ and the bathochromical shift indicated that the molecule attached to the oligonucleotide is sensitive to the presence of a duplex or a random coil form. The UV spectra indicated a change in hyperchromicity between 340 and $380 \mathrm{~nm}$, the difference being maximum around $366 \mathrm{~nm}$, so melting curves were recorded at $366 \mathrm{~nm}$. Melting curves were recorded simultaneously at $260 \mathrm{~nm}$ and $366 \mathrm{~nm}$ for comparison purposes (Figure 3). Melting temperatures at these two wavelengths were similar, although at $366 \mathrm{~nm}$ the duplex showed a lower Tm (see for example compound $2 \mathrm{~T}_{\mathrm{m}}: 42.9^{\circ} \mathrm{C}$ at $366 \mathrm{~nm}$ and $43.2^{\circ} \mathrm{C}$ at $260 \mathrm{~nm}$, Table 3). This indicates that base pair dissociation observed at end of the oligonucleotide (measured at $366 \mathrm{~nm}$ where the fluorescent tag is located) happens at a slightly lower temperature of the global melting of the duplex (measured at $260 \mathrm{~nm}$ ). A similar behaviour has been described for fluorescent compounds attached in the middle a DNA duplex $(15,16)$. The fluoresceine octamer 5 had a melting temperature of the same range than octamers carrying the isoquinoline imidazo[1,2-a]azine core with the cyclohexyl group (1a) 2 and 3 (Table 3). Surprisingly, at $493 \mathrm{~nm}$ it had a slightly higher melting temperature $\left(\mathrm{Tm} 44.8^{\circ} \mathrm{C}\right.$ at $493 \mathrm{~nm}$, $\operatorname{Tm} 44.2^{\circ} \mathrm{C}$ at $\left.260 \mathrm{~nm}\right)$.

Next we studied the effects of duplex denaturation in fluorescence. Fluorescent spectra of selfcomplementary duplex 2 in $1 \mathrm{M} \mathrm{NaCl}$ and $100 \mathrm{mM}$ sodium phosphate buffer $\mathrm{pH}=7$ at a concentration of $2.3 \mu \mathrm{M}$ at different temperatures were recorded. Figure $2 \mathrm{~b}$ shows the fluorescent spectra at $27^{\circ} \mathrm{C}$ and 53 ${ }^{\circ} \mathrm{C}$. Excitation was set at $345 \mathrm{~nm}$ Absorption maxima of oligonucleotides 2-4 at high and low temperatures are summarized in Table 4. A strong increase in fluorescence was observed upon duplex denaturation. These results and the slight increase in $\mathrm{T}_{\mathrm{m}}$ indicates that the fluorescent label interacts 
with the DNA duplex most probably as an end cap and the complex has a lower florescence. Upon duplex denaturation, the fluorescent label changes the environment duplicating the fluorescence emission. These effects were more intense in octamers carrying compound 1a (oligonucleotides $\mathbf{2}$ and $\mathbf{3}$ ) than those carrying compound $\mathbf{1 b}$ (oligonucleotide $\mathbf{4}$ ). This effect may be a consequence of the conformational preference of the isoquinoline imidazo[1,2-a]azine core containing a cyclohexyl substituent to stack over the terminal nucleobase described above. The fluoresceine octamer $\mathbf{5}$ does not increase the fluorescence upon heating, but, on the contrary, a clear decrease on the fluorescence properties is observed (Table 4).

In summary, dipolar isoquinoline derivatives 1a-b readily prepared by MCR are efficient and inexpensive reagents for introducing of fluorescent labels into synthetic oligonucleotides. Reagent 1a is particularly useful as it produces fluorescence-labeled oligonucleotides that are sensitive to hybridization and have duplex-stabilizing properties. Next we studied the capacity of fluorescencelabeled oligonucleotides to monitor cellular uptake.

\section{Cell uptake experiments.}

A 25 mer oligonucleotide sequence with an amino group at the 3'-end (Table1) was also prepared. This sequence corresponds to an antisense oligonucleotide known as GEM91 (17), which is complementary to the initiation codon of gag gene of HIV-1 RNA. Reaction of 3'-amino GEM91 with 1a yielded the expected fluorescence-labeled oligonucleotide (6) in excellent yields $(85 \%$ conversion judged by HPLC, 71\% isolated yield). The resulting product was used in the transfection assays without further purification.

We first performed flow cytometry experiments with the model isoquinoline compound 1c in order to assess the potential toxicity of the dye. HT-29 cells were incubated for $8 \mathrm{~h}$ with dipole 1c and analyzed by flow cytometry. The percentage of living or dead cells remained almost constant at all concentrations of 1c, and was very similar to the control value (see Supplementary Material). These results support the notion that this compound has a low toxicity profile. 
We then performed confocal microscopy experiments to analyze the distribution of the compound 1c inside the cells. Compound 1c was detected in the cytoplasmatic region and formed well defined aggregates (see Supplementary Material). The analogous methyl ester dipole 1d (8) was analyzed under the same conditions and showed a similar distribution pattern (see Supplementary Material).

We then performed further confocal microscopy experiments to optimize the conditions in order to evaluate the capacity of conjugate 6 to penetrate HeLa cells in the presence (or absence) of Lipofectamine $^{\mathrm{TM}} 2000$. When cells were incubated with conjugate $6(20 \mu \mathrm{M})$ for $4 \mathrm{~h}$, no fluorescence was detected, whereas the same product in the presence of Lipofectamine ${ }^{\mathrm{TM}} 2000$ penetrated the cytoplasmatic region. Longer incubation times $(22 \mathrm{~h})$ with conjugate $6(20 \mu \mathrm{M})$ in the presence of Lipofectamine $^{\mathrm{TM}} 2000$, induced strong cell toxicity and no living cells were found. This result may reflect the toxicity of Lipofectamine under these conditions.

\section{Conclusions}

Here we describe the use of unexpensive reagents in the synthesis of oligonucleotides carrying highly sensitive fluorophores. The acid fluoride derivative of the fluorophore required for the preparation of the fluorescent-labeled oligonucleotides was synthesized in high yield in a one-pot reaction using an efficient MCR which has been described previously (8). The acyl fluorides reacted efficiently in aqueous buffers at $\mathrm{pH} 9$ with amino-oligonucleotides to yield the desired conjugates. The resulting oligonucleotides show intense fluorescent properties in presence of ions, have slightly improved hybridization properties and are sensitive to denaturation. Flow cytometry and confocal microscopy experiments showed a low toxicity profile and good cell membrane permeability respectively for dyes

1c and 1d. Oligonucleotide 6 had the capacity to penetrate cells in presence of Lipofectamine ${ }^{\mathrm{TM}} 2000$ transfection reagent. 
Acknowledgments. This study was supported by the "Dirección General de Investigación Científica y Técnica" (grant BFU2007-63287, CTQ2010-20541 and CTQ2009-07758), and the Generalitat de Catalunya (2009/SGR/208). N. K. thanks the DGICYT for Ph. D. fellowship.

Supporting Information Available. Structure of the most energetically stable conformations of 1a and 1b conjugates by molecular mechanics (MM) conformational searches and geometry optimization. Flow cytometry experiments with dipolar amide 1c. Confocal microscopy images from cell uptake experiments. Mass spectrometry, HPLC analysis and melting curves of purified oligonucleotides. This material is available free of charge via the internet at http://pubs.acs.org

\section{References}

(1) Mayer, A., and Neuenhofer, S. (1994) Luminescent labels - more than just an alternative to radioisotopes? Angew. Chem. Int. Ed. 33, 1044-1072.

(2) Gait, M. J. (1991) DNA/RNA synthesis and labeling. Curr. Opin. Biotechnol. 2, 61-68.

(3) Wang, K., Tang, Z., Yang, C. J., Kim, Y., Fang, X., Li, W., Wu, Y., Medley, C.D., Cao, Z., Li, J., Colon, P., Lin H., and Tan, W. (2009) Molecular engineering of DNA: Molecular Beacons. Angew. Chem. Int. Ed. 48, 856-870.

(4) Schubert, F., Cech, D., Reinhardt, R., and Wiesner, P. (1992) Fluorescent labelling of sequencing primers for automated oligonucleotide synthesis. DNA Seq., 2, 273-279.

(5) Lilley, D. W., and Wilson, T. J. (2000) Fluorescence resonance energy transfer as a structural tool for nucleic acids. Curr. Opin. Mol. Biol. 4, 507-517. 
(6) Cuppoletti, A., Cho, Y., Park, J. S., Strässler, C., and Kool, E.T. (2005) Oligomeric fluorescent labels for DNA. Bioconjugate Chem. 16, 528-534.

(7) Singh, S., and Singh R. K. (2007) Synthesis and fluorescence studies of some new fluorophores and their effect on hybridization of oligodeoxyribonucleotides. J. Fluoresc. 17, 139-148.

(8) Arévalo, M. J., Kielland, N., Masdeu, C., Miguel, M., Isambert, N., and Lavilla, R. (2009) Multicomponent Access to functionalized mesoionic structures based on TFAA activation of isocyanides: Novel domino reactions. Eur. J. Org. Chem., 617-625.

(9) Zhu, J. and Bienaymé, H. (2005) in Multicomponent Reactions . Wiley-VCH, Weinheim.

(10) Carpino, L. A., Beyermann, M., Wenschuh, H., and Bienert, M. (1996) Peptide synthesis via amino acid halides. Acc. Chem. Res., 29, 268-274.

(11) Nelson, P. S., Kent, M., and Muthini, S. (1992) Oligonucleotide labeling methods. 3. Direct labeling of oligonucleotides employing a novel, non-nucleosidic, 2-aminobutyl-1,3-propanediol backbone. Nucleic Acids Res., 20, 6253-6259.

(12) Mergny, J. L., and Lacroix, L. (2003) Analysis of thermal melting curves. Oligonucleotides, 13, 515-537.

(13) Connolly, B. A. (1987) The synthesis of oligonucleotides containing a primary amino group at the 5'-terminus. Nucleic Acids Res., 15, 3131-3139.

(14) Davies, M. J., Shah, A., and Bruce, I. J., (2000) Synthesis of fluorescently labelled oligonucleotides and nucleic acids. Chem. Soc. Rev., 29, 97-107.

(15) Eritja, R., Kaplan, B.E., Mhaskar, D., Sowers, L.C., Petruska, J., and Goodman, M.F. (1986) Synthesis and properties of defined DNA oligomers containing base mispairs involving 2-aminopurine. Nucleic Acids Res., 14, 5869-5884. 
(16) Ramzaeva, N., Rosemeyer, H., Leonard, P., Mühlegger, K., Bergmann, F., von der Eltz, H., and Seela, F. (2000) Oligonucleotides functionalized by fluoresceine and rhodamine dyes: Michael addition of methyl acrylate to 2'-deoxypseudouridine. Helv. Chim. Acta, 83, 1108-1126.

(17) Lisziewicz, J., Sun, D., Weichold, F. F., Thierry, A. R., Lusso, P., Tang, J, Gallo, R. C., and Agrawal, S. (1994) Antisense oligodeoxynucleotide phosphorothioate complementary to gag mRNA blocks replication of human immunodeficiency virus type 1 in human peripheral blood cells. Proc. Natl. Acad. Sci. USA, 91, 7942-7946. 
TABLES.

Table 1. Mass spectra and UV maxima of fluorescent oligonucleotides prepared in this study.

\begin{tabular}{|l|l|l|l|l|}
\hline$\#$ & Sequence $\left(5^{\prime}-3^{\prime}\right)$ & $\begin{array}{l}\text { MS } \\
(\text { expected })\end{array}$ & MS (found) & UV $_{\text {max }}, \mathrm{nm}$ \\
\hline $\mathbf{2}$ & CCAATTGG-NHCO-1a & 2910.1 & 2911.8 & 260,347 \\
\hline $\mathbf{3}$ & TTCCGGAA- NHCO-1a & 2910.1 & 2906.8 & 260,346 \\
\hline $\mathbf{4}$ & CCAATTGG-NHCO-1b & 2918.3 & 2914.9 & 260,345 \\
\hline $\mathbf{5}$ & TTCCGGAA-NHCO-FITC & 3008.9 & 3004.4 & 260,493 \\
\hline $\mathbf{6}$ & $\begin{array}{l}\text { CTCTCGCACCCATCTCTCTCCTTCT } \\
\text { NHCO-1a }\end{array}$ & 7892.3 & 7870.2 & 267,348 \\
\hline
\end{tabular}

Table 2. Thermodynamic parameters for duplex-to-random-coil transitions ${ }^{*}(1 \mathrm{M} \mathrm{NaCl}$ and $100 \mathrm{mM}$ sodium phosphate buffer at $\mathrm{pH}=7$ ).

\begin{tabular}{|c|c|c|c|c|c|c|}
\hline \# & Duplex & $\operatorname{Tm}\left[{ }^{\circ} \mathrm{C}\right]^{* *}$ & $\begin{array}{l}\Delta H \\
{[\mathrm{Kcal} / \mathrm{mol}]}\end{array}$ & $\begin{array}{l}\Delta S \\
{[\mathrm{Kcal} / \mathrm{mol} . \mathrm{K}]}\end{array}$ & $\begin{array}{l}\Delta G \\
{[\mathrm{Kcal} / \mathrm{mol}]}\end{array}$ & $\begin{array}{l}\Delta \Delta G^{* * *} \\
{[\mathrm{Kcal} / \mathrm{mol}]}\end{array}$ \\
\hline & ${ }^{5} \mathrm{CCAATTGG}^{3}$ & 33.3 & -119.5 & -340.5 & -18.0 & 0 \\
\hline 2 & ${ }^{5}$ CCAATGG-1a ${ }^{3}$ & 41.1 & -116.8 & -322.5 & -20.6 & 1.3 \\
\hline \multirow[t]{2}{*}{$\overline{4}$} & ${ }^{5}$ CCAATGG-1 $\mathbf{b}^{3}$ & 34.0 & -103.7 & -288.3 & -17.7 & -0.15 \\
\hline & ${ }^{5}$ TTCCGGAA $^{3}$ & 31.8 & -107.5 & -303.0 & -17.2 & 0 \\
\hline 3 & ${ }^{5}$ TTCCGGAA-1a ${ }^{3}$ & 44.2 & -107.0 & -287.8 & -21.2 & 2 \\
\hline
\end{tabular}

${ }^{(*)} \Delta G$ is calculated at $25^{\circ} \mathrm{C}$, with the assumption that $\Delta H$ and $\Delta S$ do not depend on temperature; analysis was carried out with melting temperatures obtained from denaturation curves. ${ }^{(*)} \mathrm{Tm}$ calculated at $4 \mu \mathrm{M}$ duplex concentration. $(* * *) \Delta \mathrm{G}$ (modified octamer)- $\Delta \mathrm{G}$ (unmodified octamer) / 2 fluorescent molecules. 
Table 3. Melting temperatures of modified and unmodified duplex at different $\lambda$.

\begin{tabular}{|c|c|c|c|c|}
\hline \# & Oligonucleotide & $\begin{array}{c}\text { Abs. }(260 \mathrm{~nm} \text {, } \\
\left.7^{\circ} \mathrm{C}\right)\end{array}$ & $\begin{array}{l}\operatorname{Tm}\left({ }^{\circ} \mathrm{C}\right) \\
(260 \mathrm{~nm})\end{array}$ & $\begin{array}{c}\operatorname{Tm}\left({ }^{\circ} \mathrm{C}\right) \\
(\lambda)^{(*)}\end{array}$ \\
\hline 2 & ${ }^{5}$ CCAATGG-1a ${ }^{3 \prime}$ & 0.59 & 433.2 & 42.9 \\
\hline 3 & ${ }^{5^{\prime}}$ TTCCGGAA-1a ${ }^{3}$ & 0.48 & 45.9 & 35.4 \\
\hline 4 & ${ }^{5^{\prime} \text { CCAATGG-1b }}{ }^{3 \prime}$ & 0.61 & 37.2 & 36.8 \\
\hline 5 & $5^{\prime}$ TTCCGGAA-FITC $^{3}$ & 0.63 & 44.2 & 44.8 \\
\hline
\end{tabular}

${ }^{\left({ }^{*}\right)}$ Melting experiments performed at $366 \mathrm{~nm}$ for 2 and 4, $364 \mathrm{~nm}$ for 3 and $493 \mathrm{~nm}$ for 5

Table 4. Fluorescence spectral data for the modified oligonucleotides before and after duplex denaturation.

\begin{tabular}{|c|c|c|c|c|c|}
\hline & $\begin{array}{c}\text { Temperature } \\
\left({ }^{\circ} \mathrm{C}\right)\end{array}$ & $\begin{array}{c}\text { Emission } \\
\text { maximum }(\mathbf{n m})\end{array}$ & $\begin{array}{l}\text { Fluorescenc } \\
\text { e } \\
\text { intensity (I) }\end{array}$ & $\mathbf{F}_{\text {RC }} / \mathbf{F}_{\mathbf{D}}$ & $\Delta \mathrm{I}(\%)$ \\
\hline \multirow{3}{*}{2} & 27 & 426 & 184 & \multirow{3}{*}{2.02} & \multirow{3}{*}{+102} \\
\hline & 52 & 420 & 271 & & \\
\hline & 53 & 429 & 371 & & \\
\hline \multirow{3}{*}{3} & 24 & 427 & 322 & \multirow{3}{*}{1.74} & \multirow{3}{*}{+74} \\
\hline & & & & & \\
\hline & 51 & 430 & 560 & & \\
\hline \multirow{3}{*}{4} & 17 & 418 & 312 & \multirow{3}{*}{1.34} & \multirow{3}{*}{+34} \\
\hline & 30 & 4 & 418 & & \\
\hline & 39 & 423 & 418 & & \\
\hline \multirow{3}{*}{5} & 20 & 522 & 117 & \multirow{3}{*}{0.82} & \multirow{3}{*}{-18} \\
\hline & & & & & \\
\hline & 60 & 520 & 96 & & \\
\hline
\end{tabular}




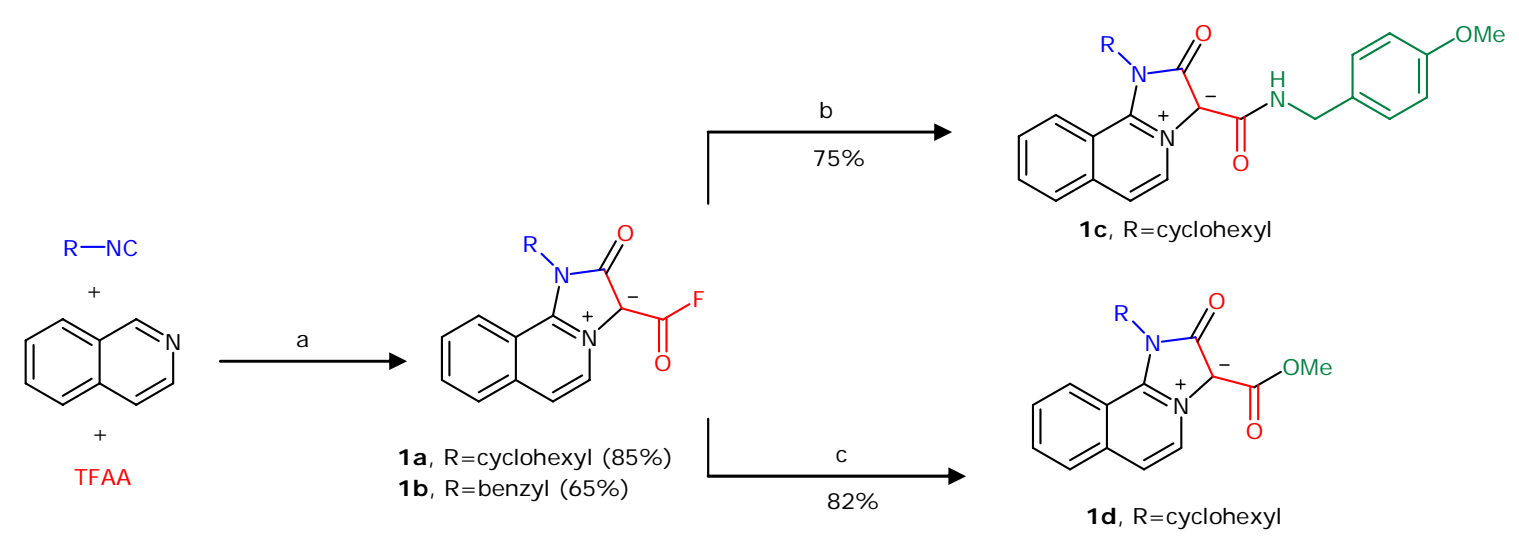

Scheme 1. 3-Component reaction of isoquinoline and isocyanides in the presence of trifluoroacetic anhydride and subsequent reaction of the resulting acyl fluoride with p-methoxybenzylamine or methanol. Reagents and conditions: a) $\mathrm{CH}_{2} \mathrm{Cl}_{2}, 14$ h, r.t., b) p-methoxybenzylamine, TEA, $\mathrm{CH}_{2} \mathrm{Cl}_{2}$ anh., r.t., overnight c) $\mathrm{MeOH}$, TEA, reflux.
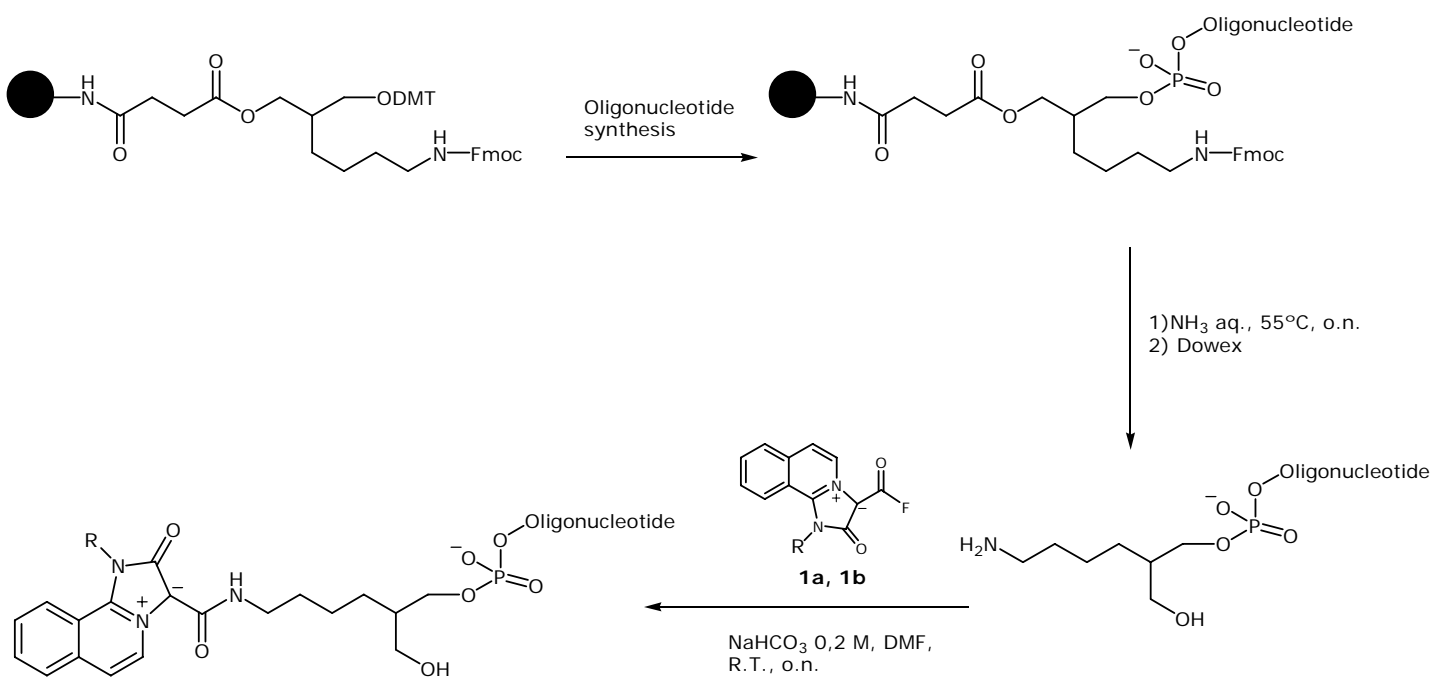

Scheme 2. Synthesis of oligonucleotides carrying a derivative of isoquinoline at the 3 '-end. 


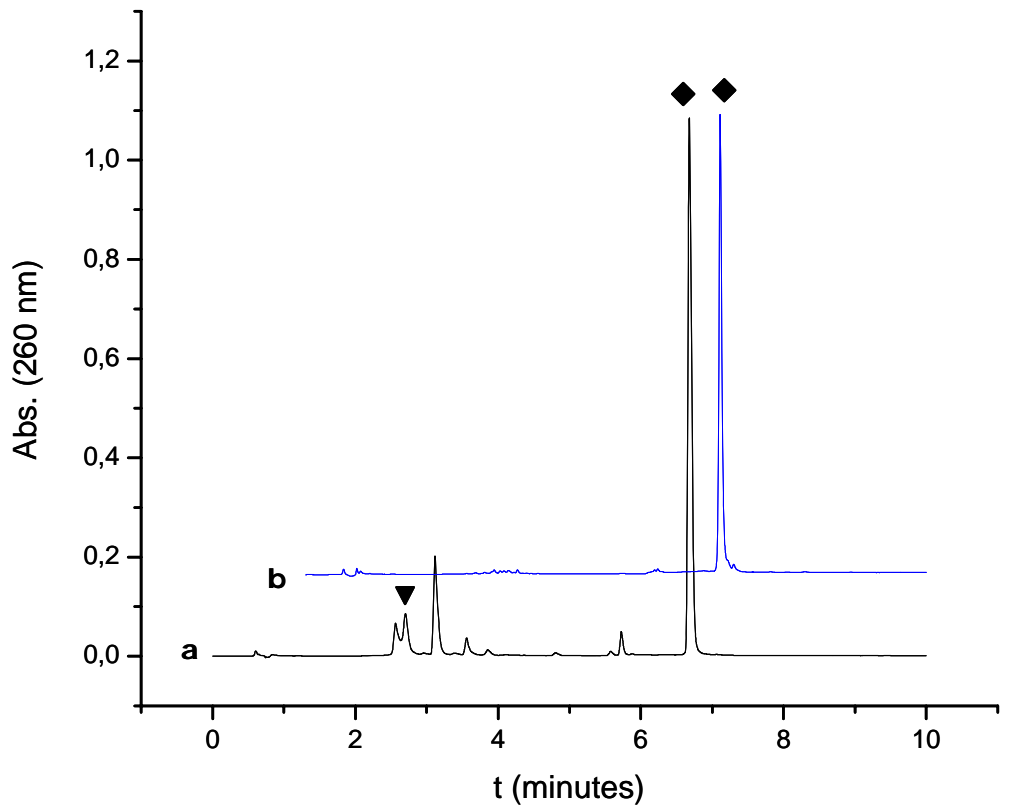

Figure 1. HPLC profiles of a) the mixture obtained after the reaction with compound 1a and aminooligonucleotide sequence A to yield compound 2 (conversion 91\%) and b) purified compound 2 . HPLC conditions: 4 min linear gradient from $0-12 \% \mathrm{~B}$, then 6 min linear gradient from $12-50 \% \mathrm{~B}$ at $60^{\circ} \mathrm{C}$. The desired oligonucleotide (compound 2) eluted at $8.7 \min (\boldsymbol{\nabla}$ stands for amino-oligonucleotide sequence A and $\bullet$ stands for oligomer 2). 

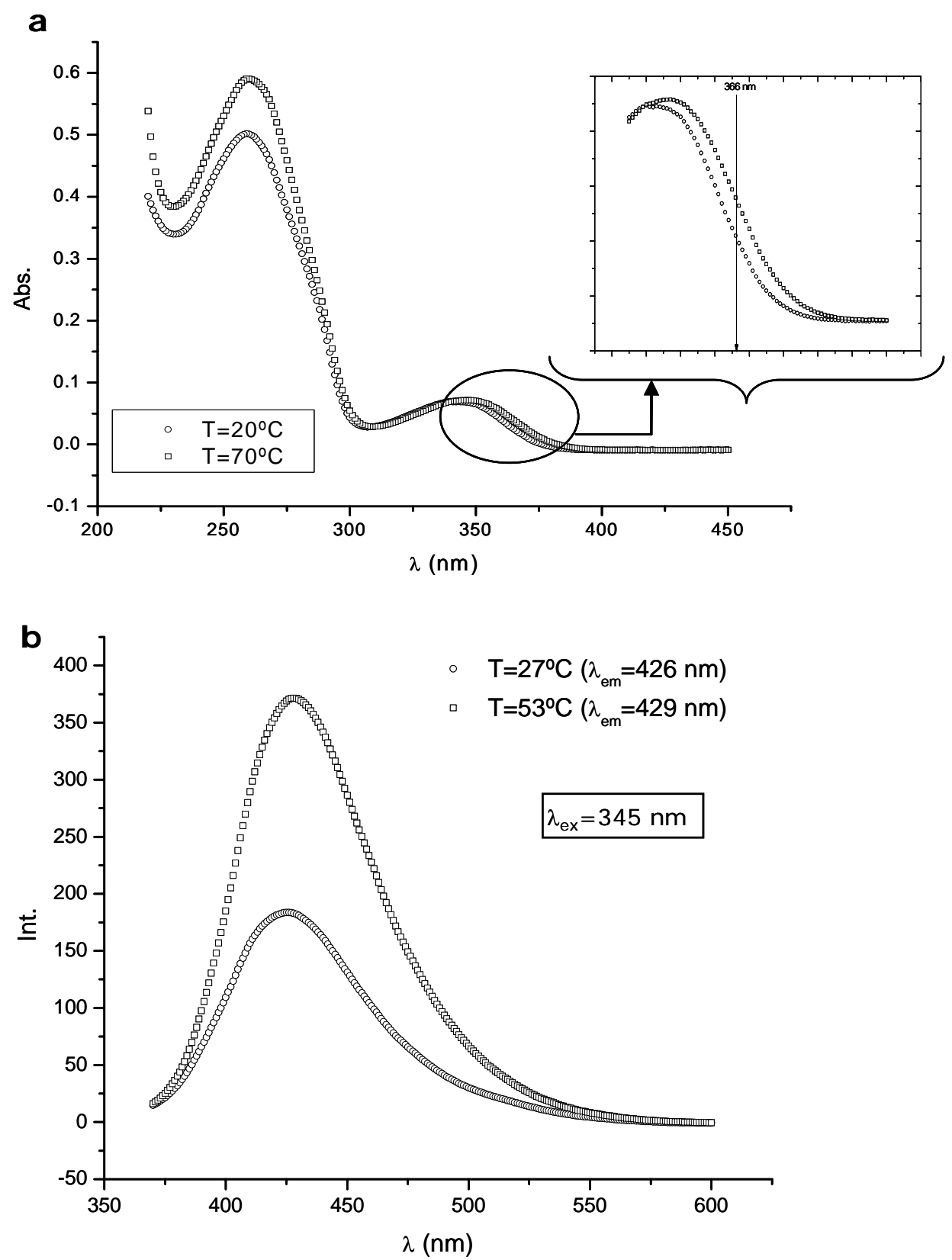

Figure 2. a) UV and b) fluorescence spectra of oligonucleotide 2. 

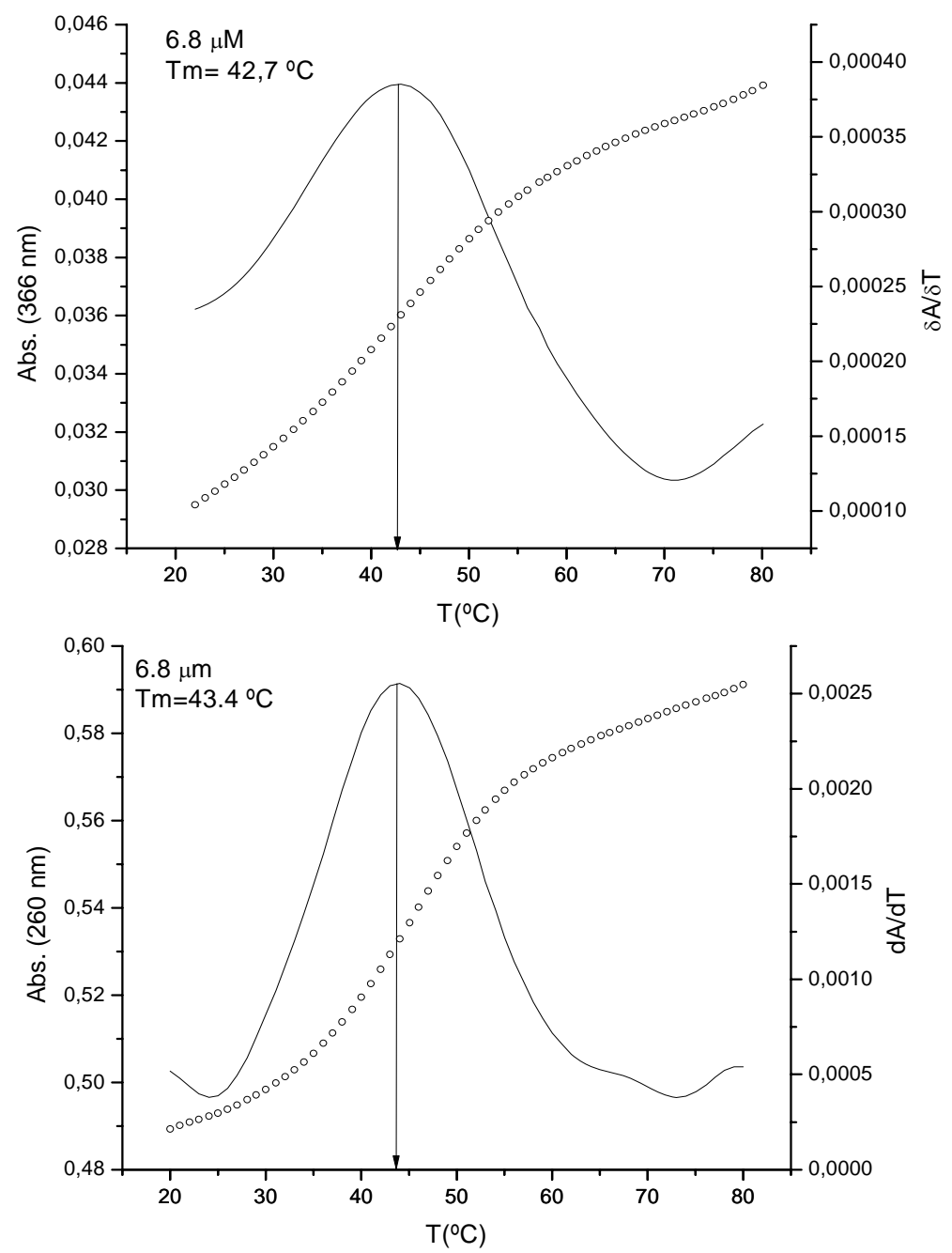

Figure 3. Melting curves of self-complementary oligonucleotide 2 measured at $260 \mathrm{~nm}$ and $366 \mathrm{~nm}$. 


\section{SYNOPSIS}

a)

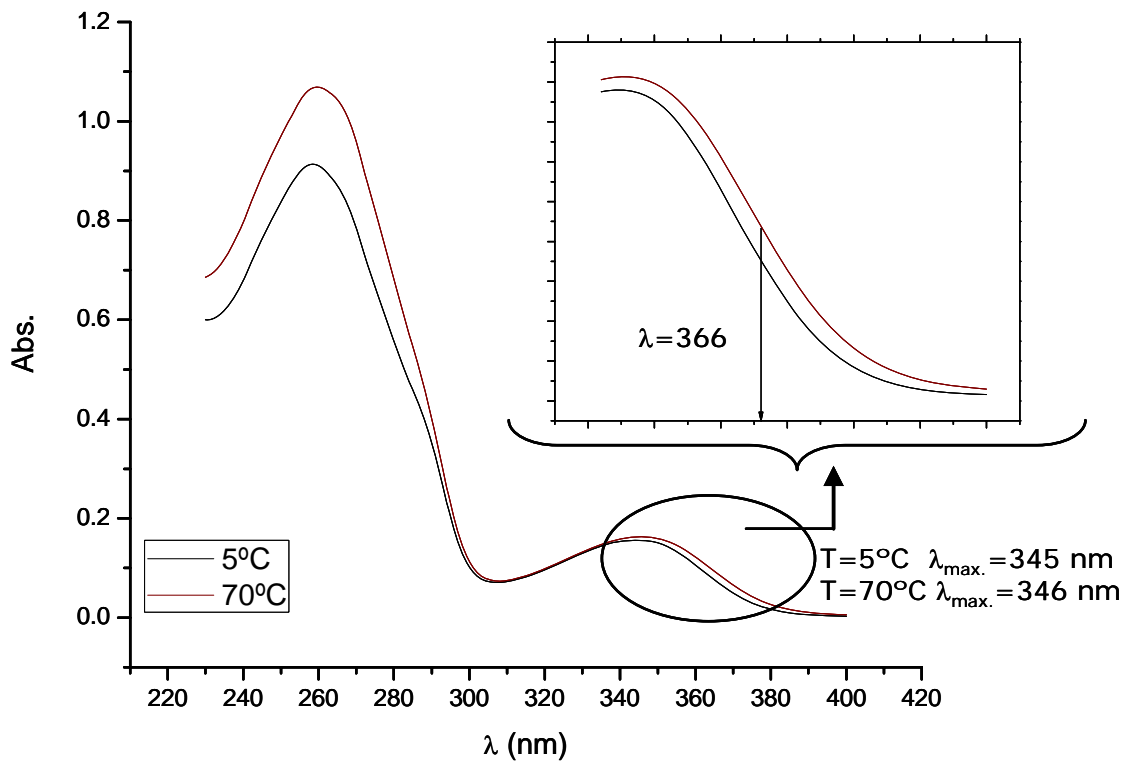




\section{Supporting data}

\section{Synthesis and properties of oligonucleotides carrying isoquinoline imidazo[1,2-a]azine fluorescent units.}

Sónia Pérez-Rentero ${ }^{\ddagger}$, Nicola Kielland ${ }^{\S}$, Montserrat Terrazas ${ }^{\ddagger}$, Rodolfo Lavilla, ${ }^{*},{ }^{, \dagger}$ and Ramon Eritja ${ }^{*, \neq}$ ${ }^{\ddagger}$ Institute for Research in Biomedicine, IQAC-CSIC, CIBER-BBN Networking Centre on Bioenginnering, Biomaterials and Nanomedicine. Baldiri Reixac 10, 08028 Barcelona, Spain.

${ }^{\S}$ Institute for Research in Biomedicine, Barcelona Science Park, Baldiri Reixac 10, 08028 Barcelona, Spain.

${ }^{\dagger}$ Laboratory of Organic Chemistry, Faculty of Pharmacy. University of Barcelona. Avda. Diagonal sn, 08028 Barcelona, Spain.

\section{SUPPORTING INFORMATION:}

Page 2. Figure S1. Structure of the most energetically stable conformations of $\mathbf{1 a}$ and $\mathbf{1 b}$ conjugates by molecular mechanics (MM) conformational searches and geometry optimization

Page 3: Figure S2. Flow cytometry experimental data.

Page 4-5: Confocal microscopy images. Figures S3-S7. 

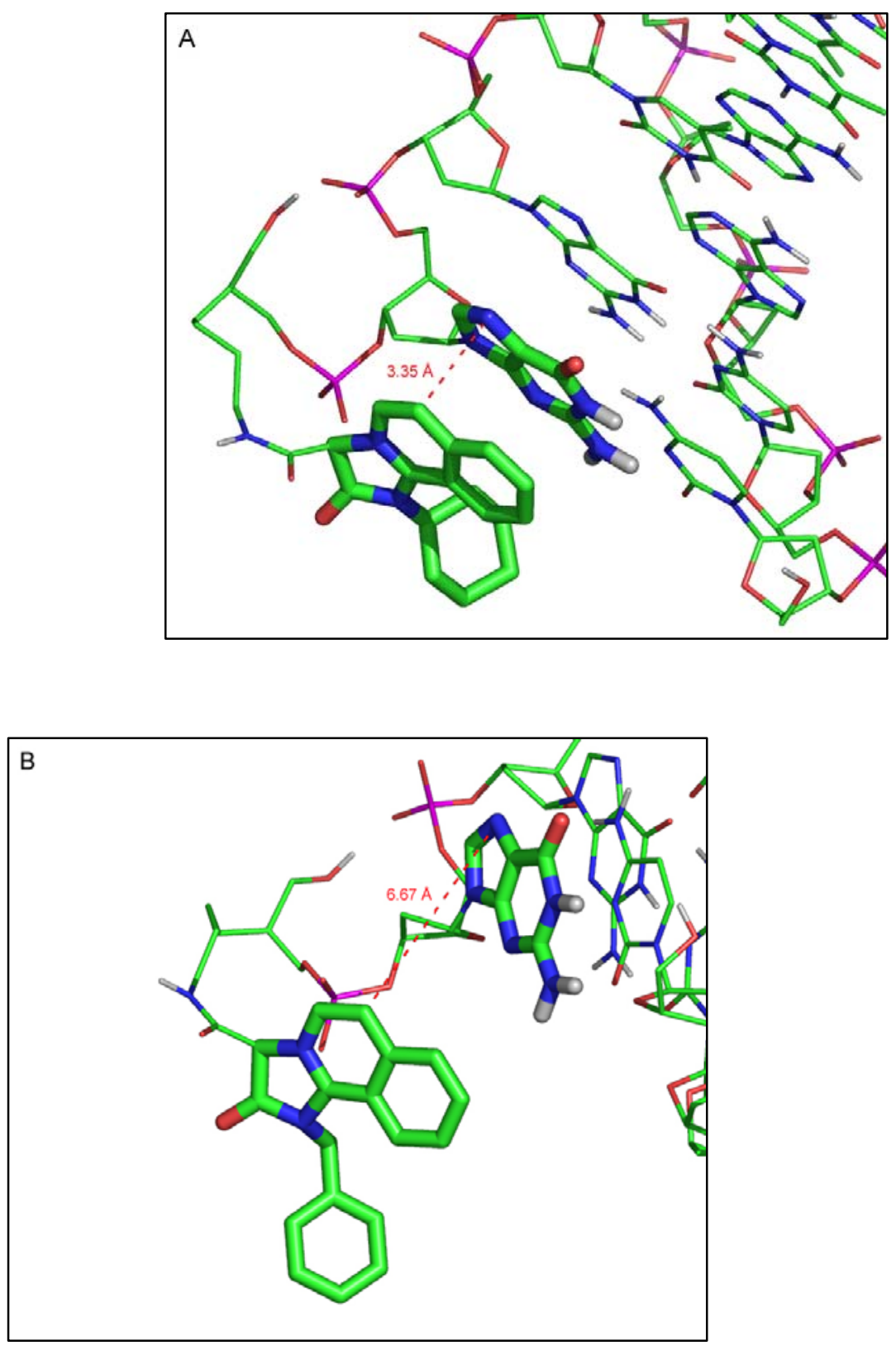

Figure S1. Most energetically stable conformations of $\mathbf{1 a}$ and $\mathbf{1 b}$ conjugates (panels A and B, respectively). The terminal guanine nucleobase and the triazine core are shown as thick lines. Distances between guanine and the isoquinoline imidazo[1,2-a]azine core are indicated. The figures were prepared with PyMOL (http://pymol.sourceforge.net/). Molecular mechanics (MM) conformational searches and geometry optimization of the most energetically stable conformers were carried out with the Amber force field by using the softwares Spartan'04 from Wavefunction and HyperChem'08 and by using water as a solvent. The duplex of DNA was kept frozen and the linker was allowed to move freely during the calculations. 
Flow cytometry experimental data:

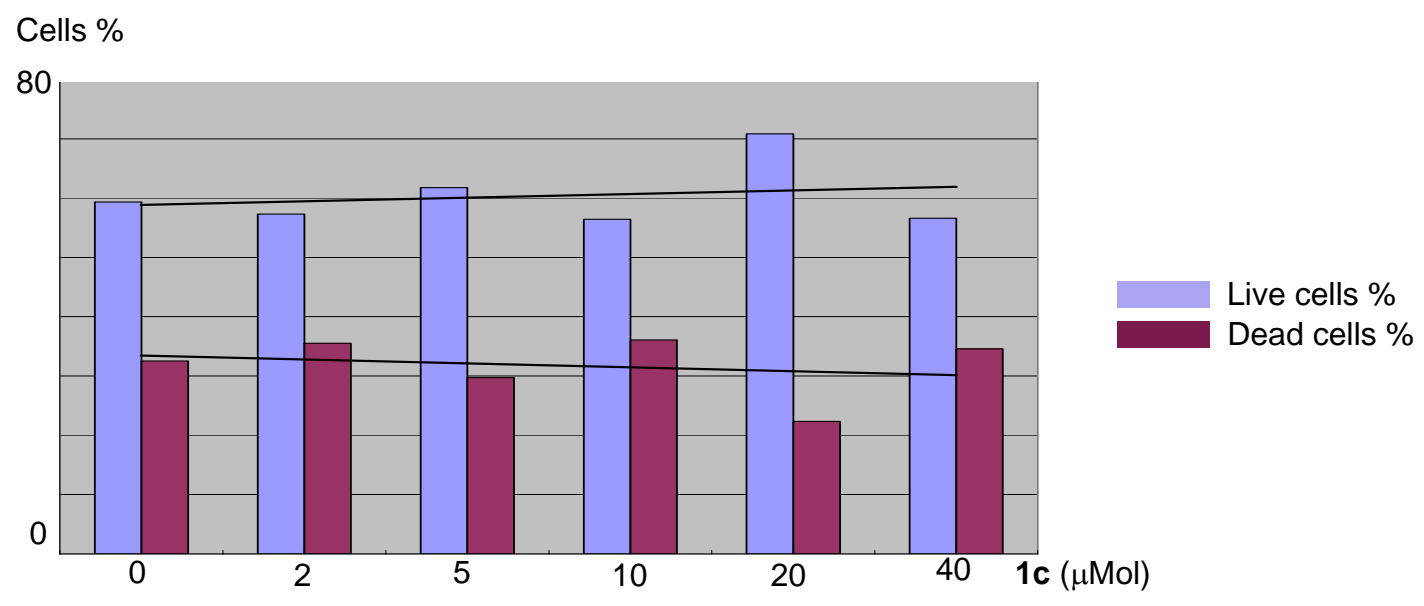

Figure S2: Evaluation of the cytotoxicity profile of 1c by flow cytometry on HT-29 cells. Incubation time $8 \mathrm{~h}$. 
Confocal microscopy images:

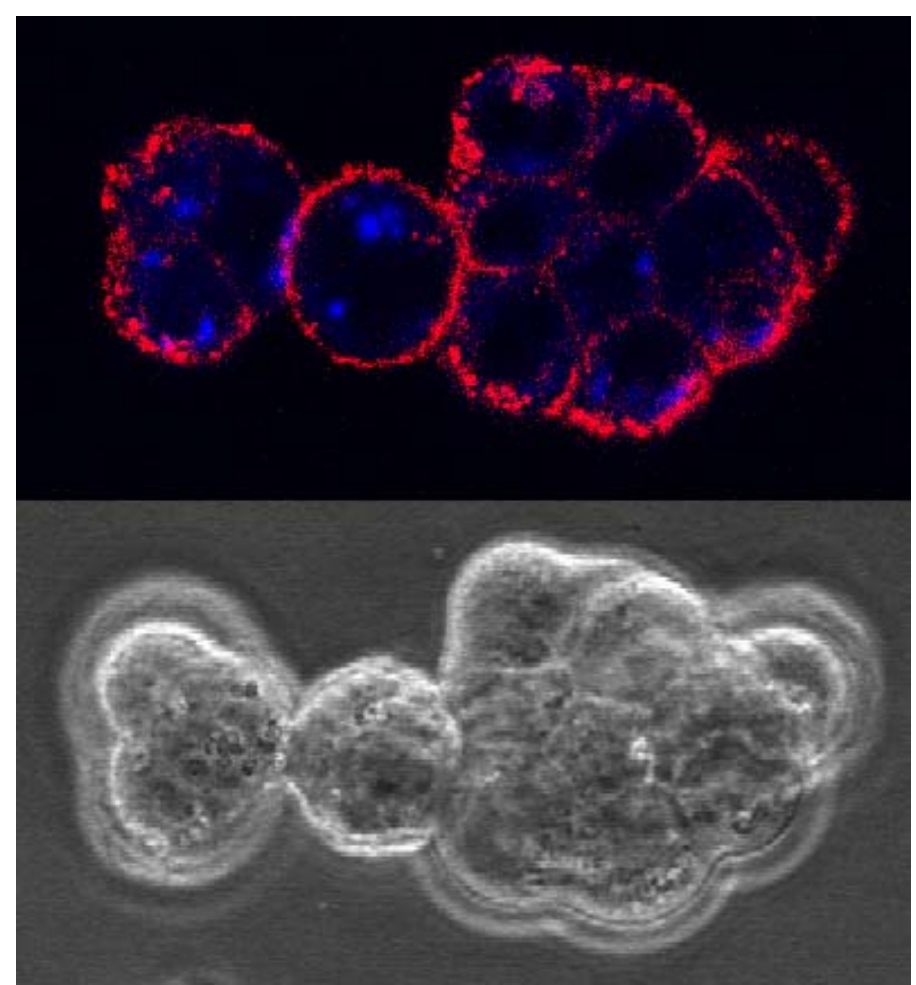

Figure S3: 1c $[20 \mu \mathrm{M}]$ in HT-29 cells (2h incubation) 


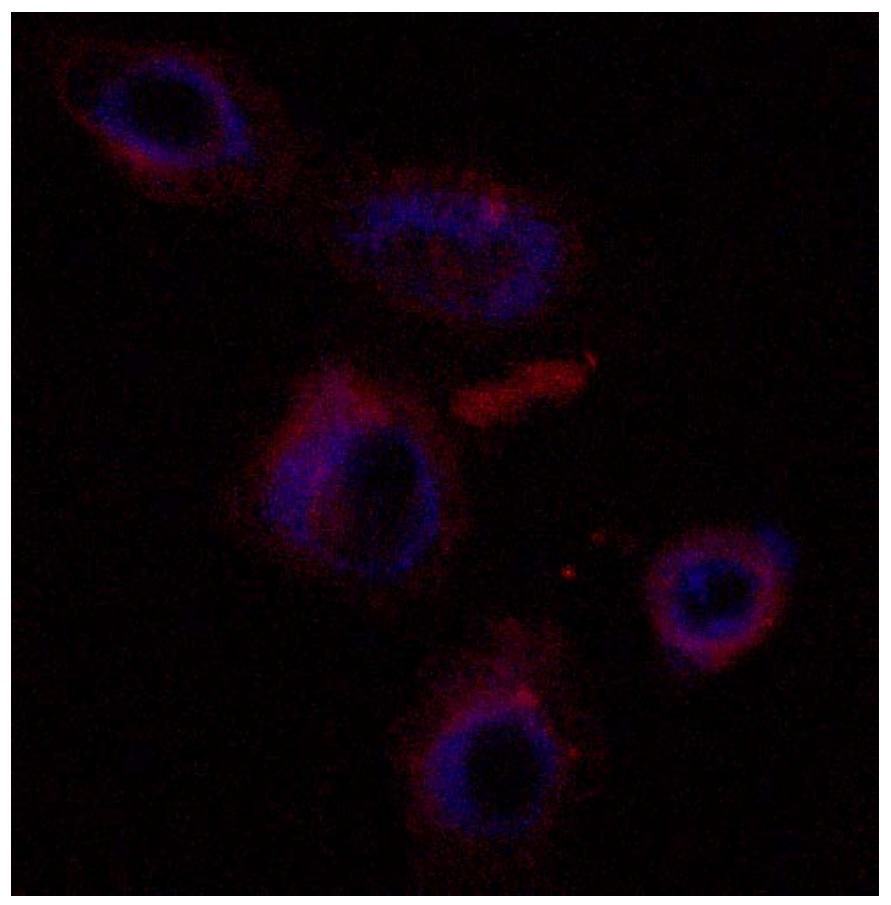

Figure S4.: 1c $[20 \mu \mathrm{M}]$ in Hela cells (4h incubation)

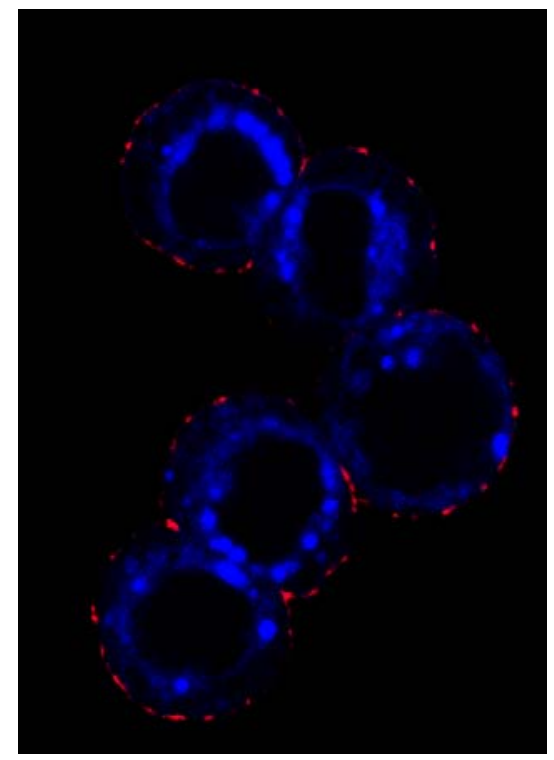

Figure S5: 1d $[20 \mu \mathrm{M}]$ in HT-29 cells (2h incubation) 


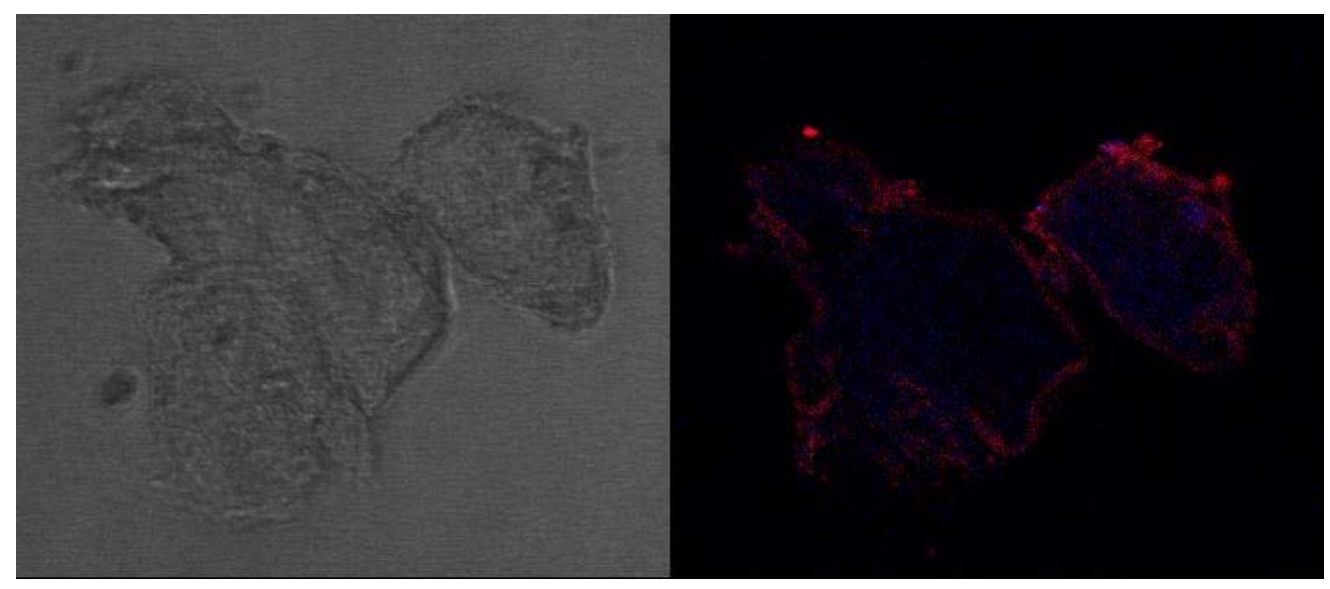

Figure S6.: Oligonucleotide 6 [20 $\mu \mathrm{M}$ ] with Lipofectamine in Hela cells (4h incubation) 


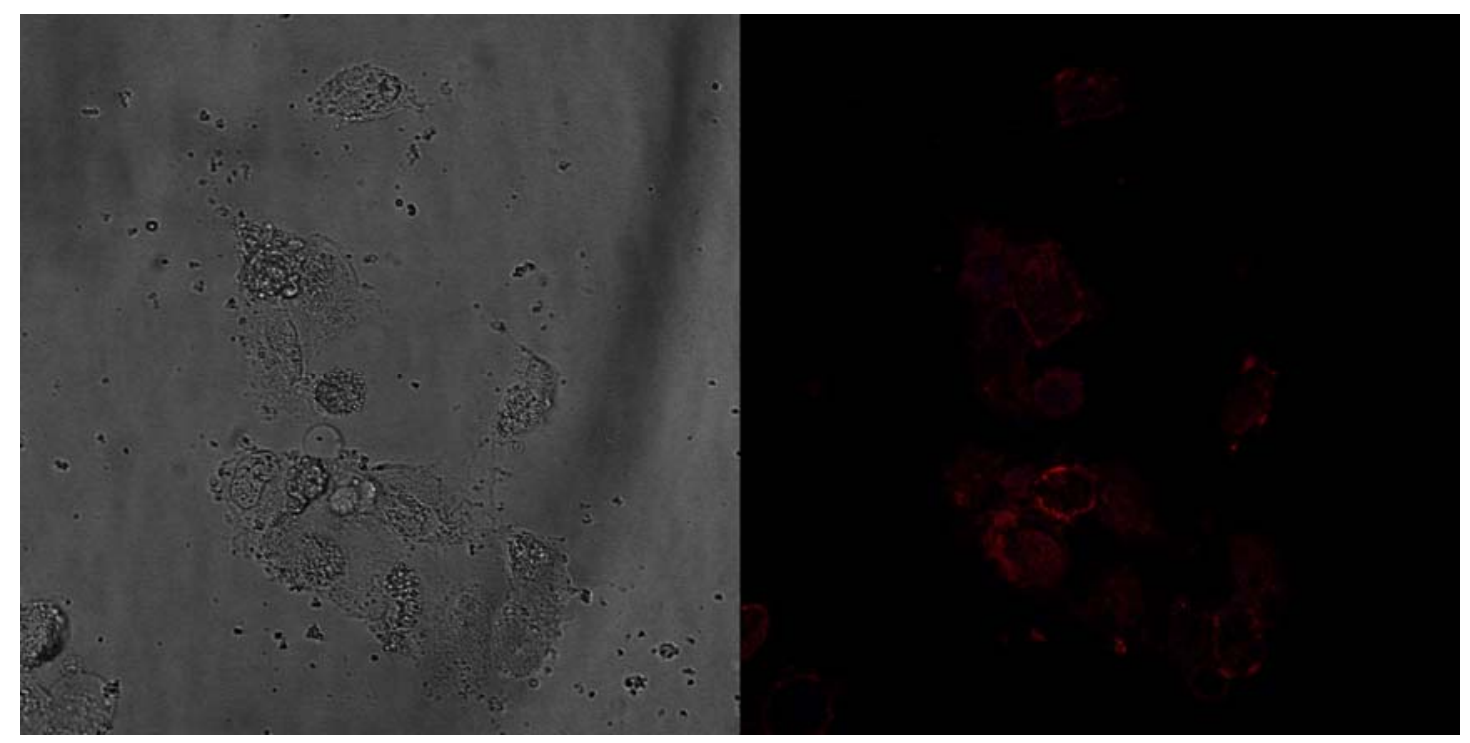

Figure S7. Oligonucleotide 6 [20 mM] with Lipofectamine in Hela cells ( $22 \mathrm{~h}$ incubation). 